\title{
Inhibitory Effect on Acrolein by Cyanidin-3-O-glucoside and Its Acrolein Adducts from the Pigment of Mynica Red
}

Xiaoli Song ${ }^{\dagger}$, Yang $\mathrm{Lu}^{\dagger}$, Bo Si๋, Yongling $\mathrm{Lu}^{\dagger}$, Qiuting Zhang ${ }^{\dagger}$, Lishuang $\mathrm{LV}^{\dagger *}$

†Department of Food Science and Technology, School of Food Science and Pharmaceutical Engineering, Nanjing Normal University, 2 Xuelin Road, Nanjing, Jiangsu 210023, People's Republic of China

$¥$ National Liquor Product Quality Supervision and Inspection Center, Suqian Product Quality Supervision \& Inspection Institute, 889 Fazhan Road, Suqian, Jiangsu 223800, People's Republic of China

Corresponding author (Dr. Lishuang Lv, Telephone/Fax: +86 25-85898183; E-mail: lishuanglv@126.com or lulishuang@njnu.edu.cn 
Figure S1. High-resolution mass spectrum of C3G-ACR

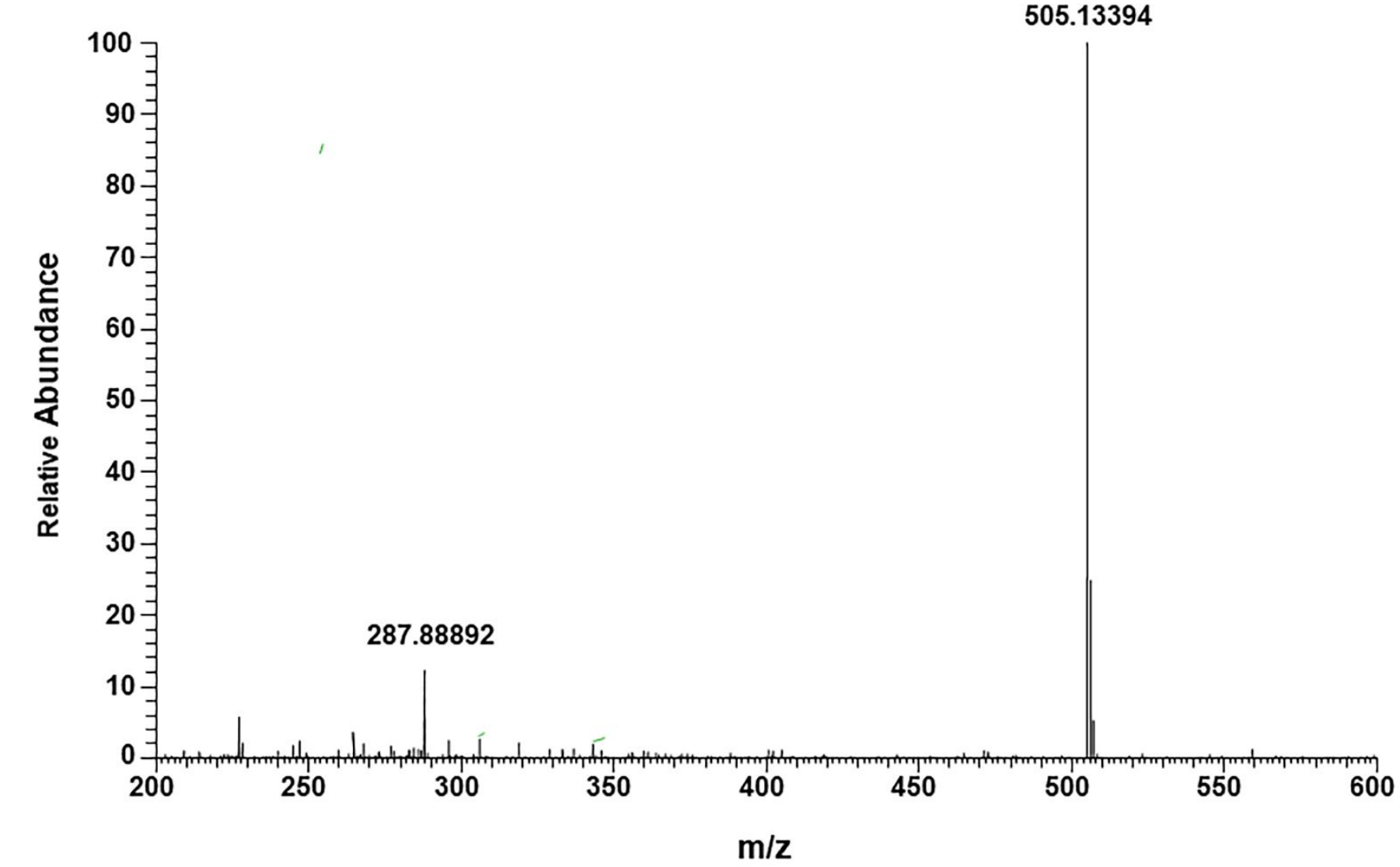


Figure S2. High-resolution mass spectrum $\left(\mathrm{MS}^{2}\right)$ of $\mathrm{C} 3 \mathrm{G}-\mathrm{ACR}$

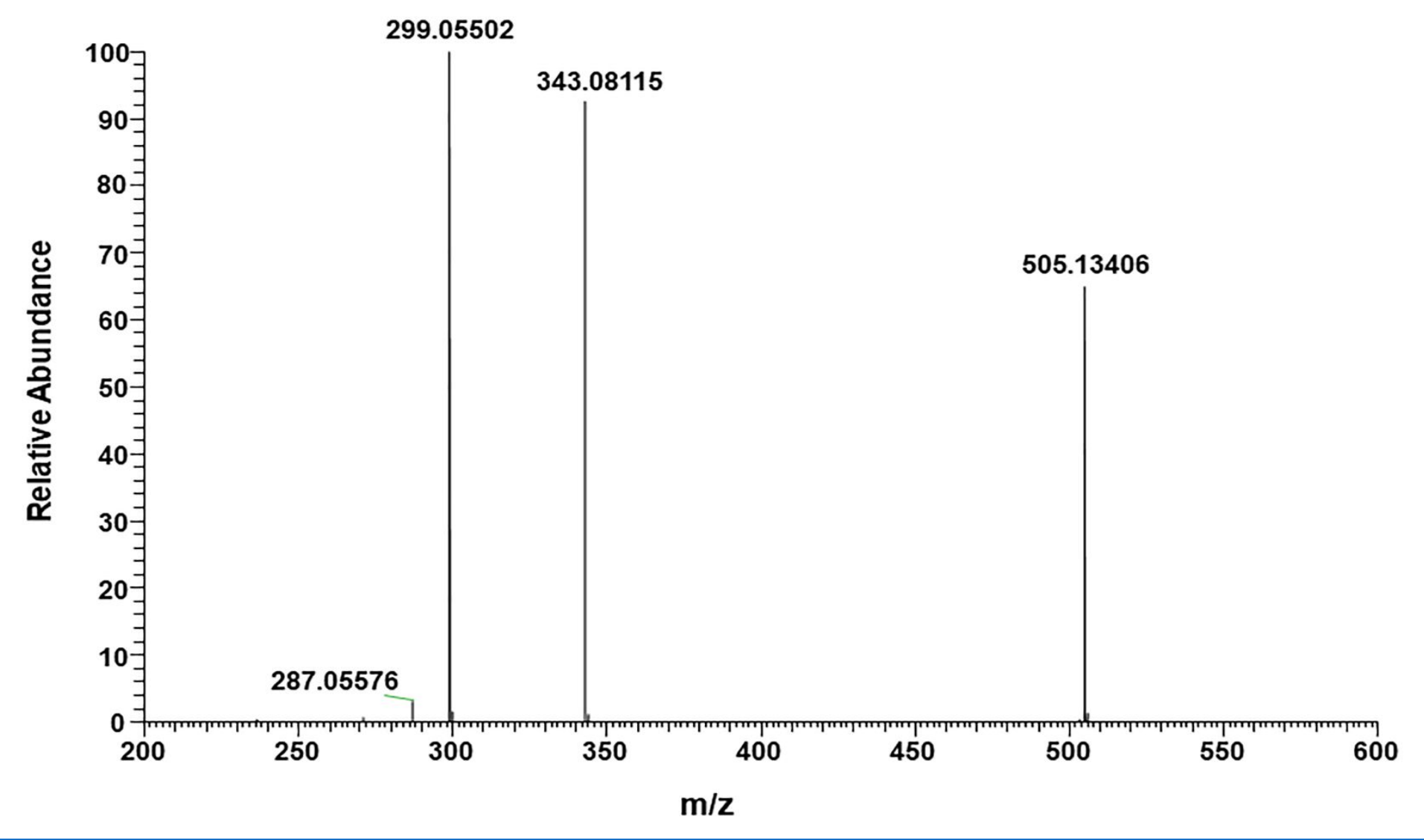


Figure S3. ${ }^{1} \mathrm{H}-\mathrm{NMR}$ spectrum of C3G-ACR

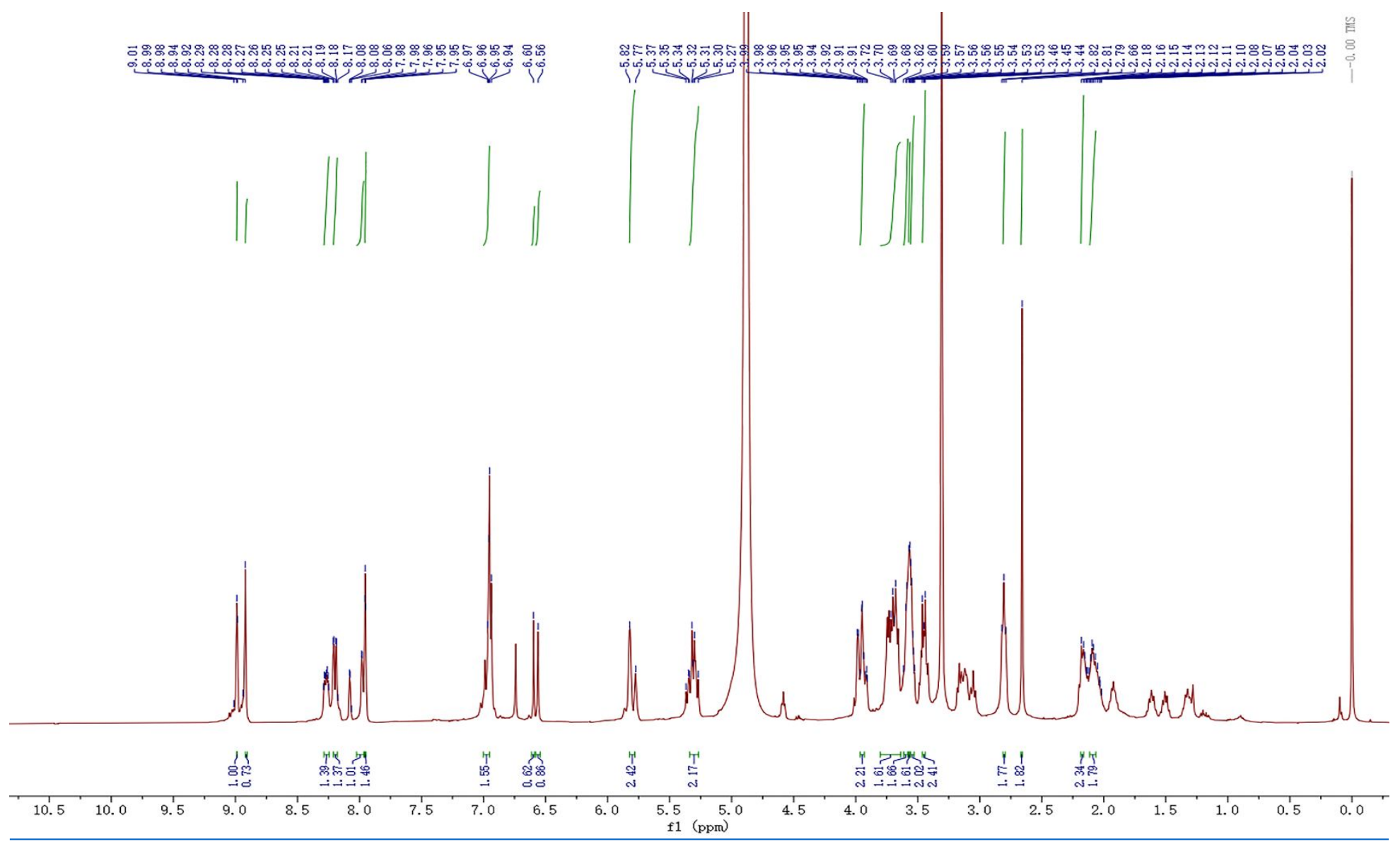


Figure S4. ${ }^{13} \mathrm{C}-\mathrm{NMR}$ spectrum of $\mathrm{C} 3 \mathrm{G}-\mathrm{ACR}$

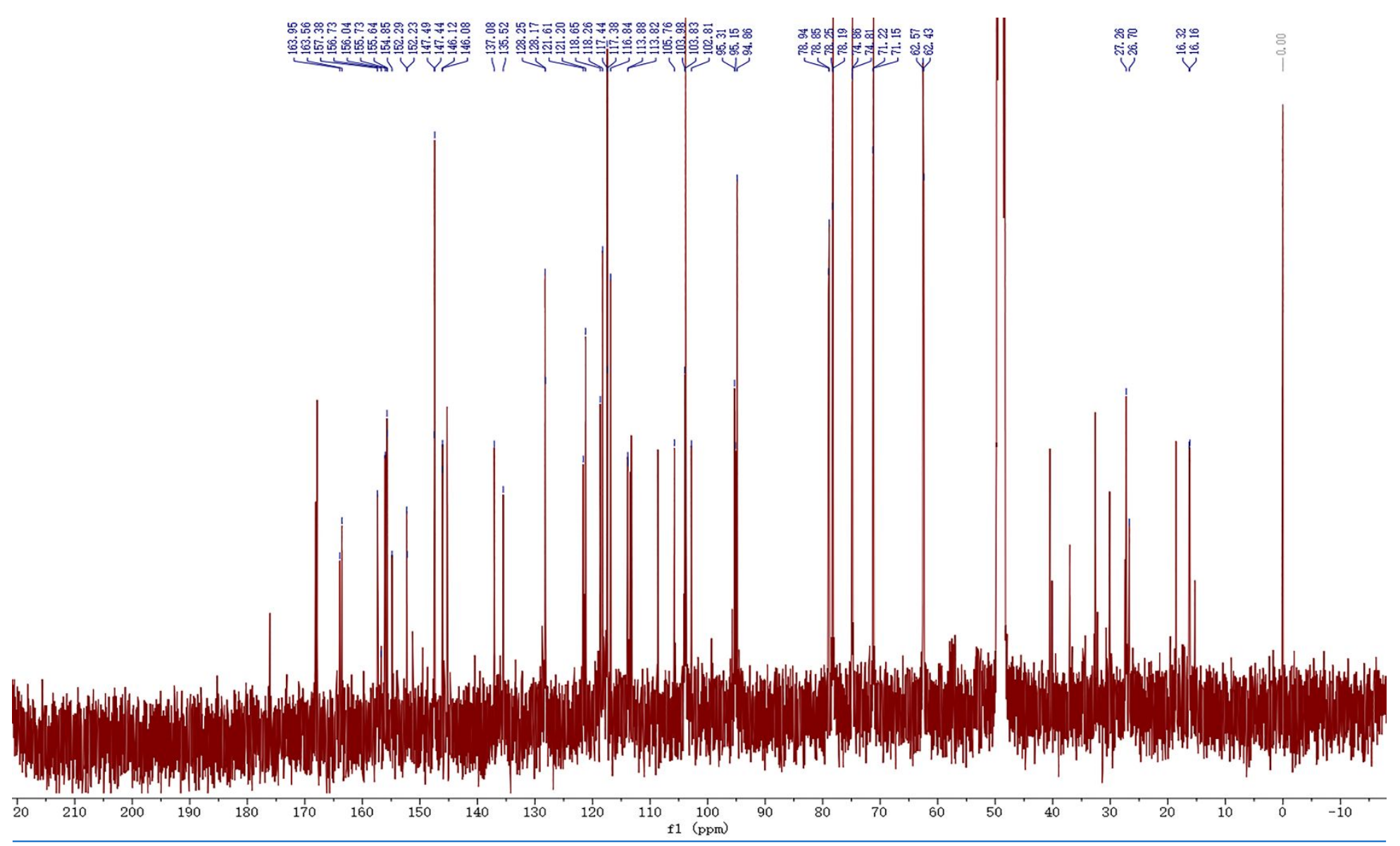


Figure S5. HSQC-NMR spectrum of C3G-ACR

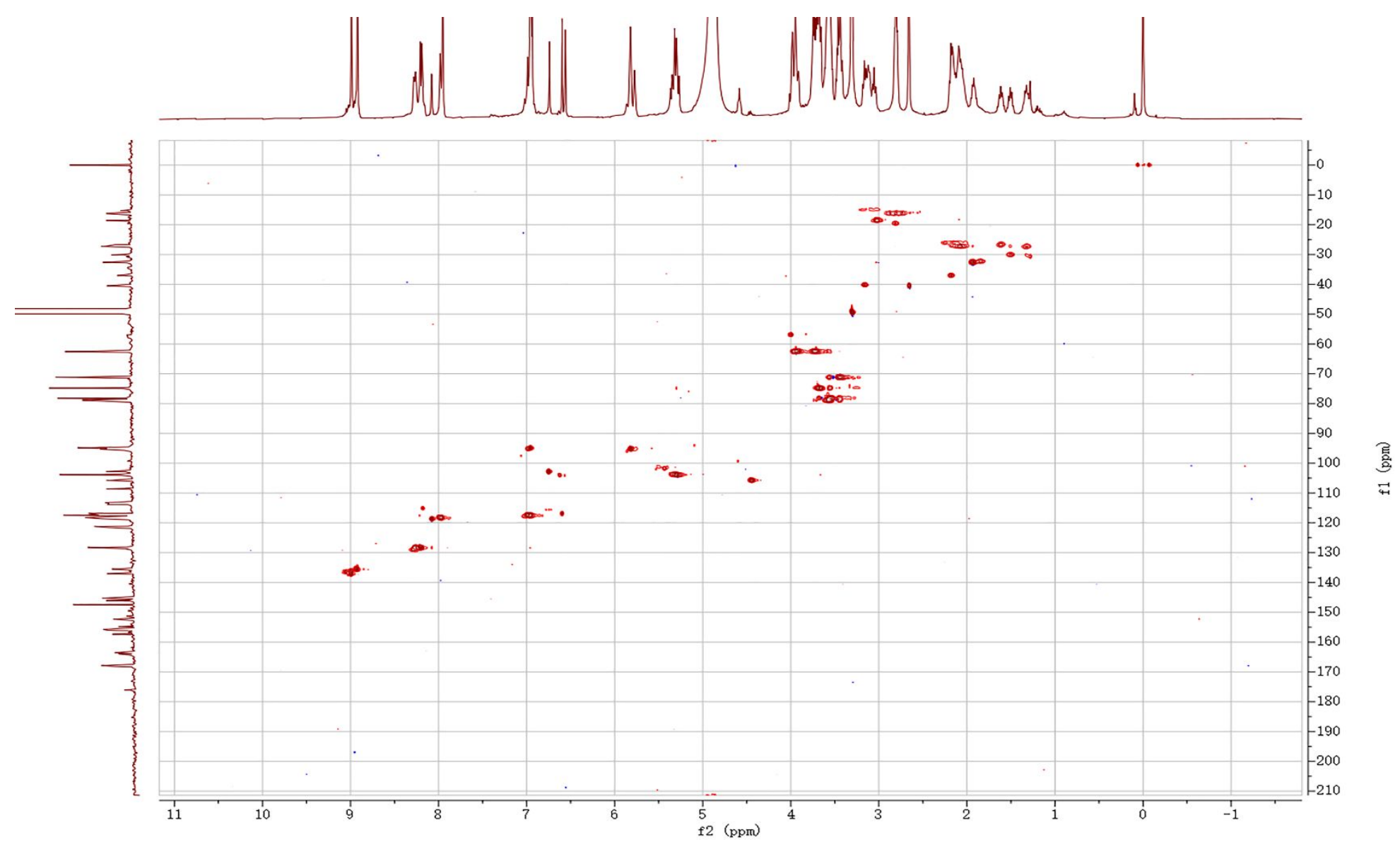


Figure S6. HMBC-NMR spectrum of C3G-ACR

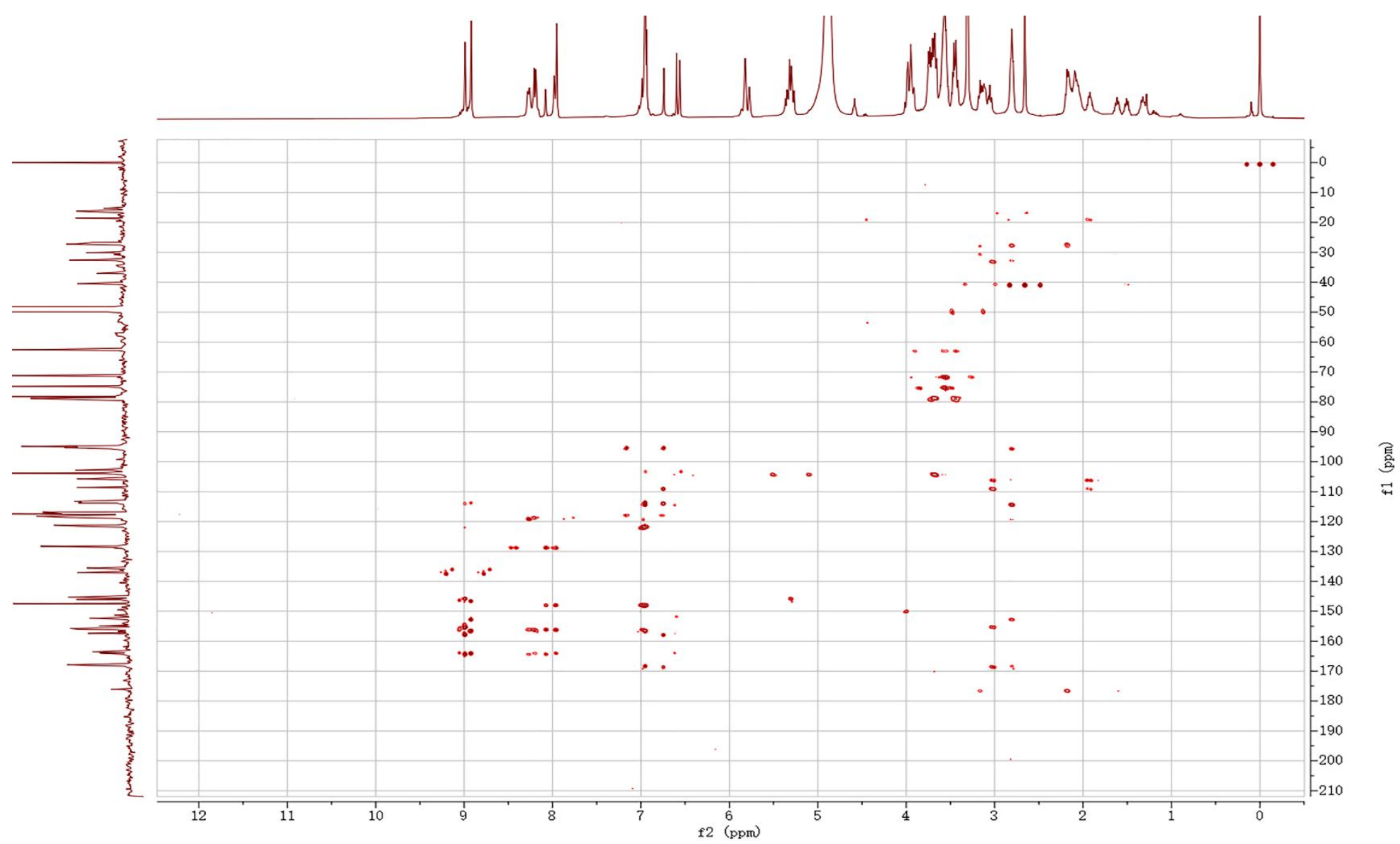


Figure S7. High-resolution mass spectrum of C3G-2ACR

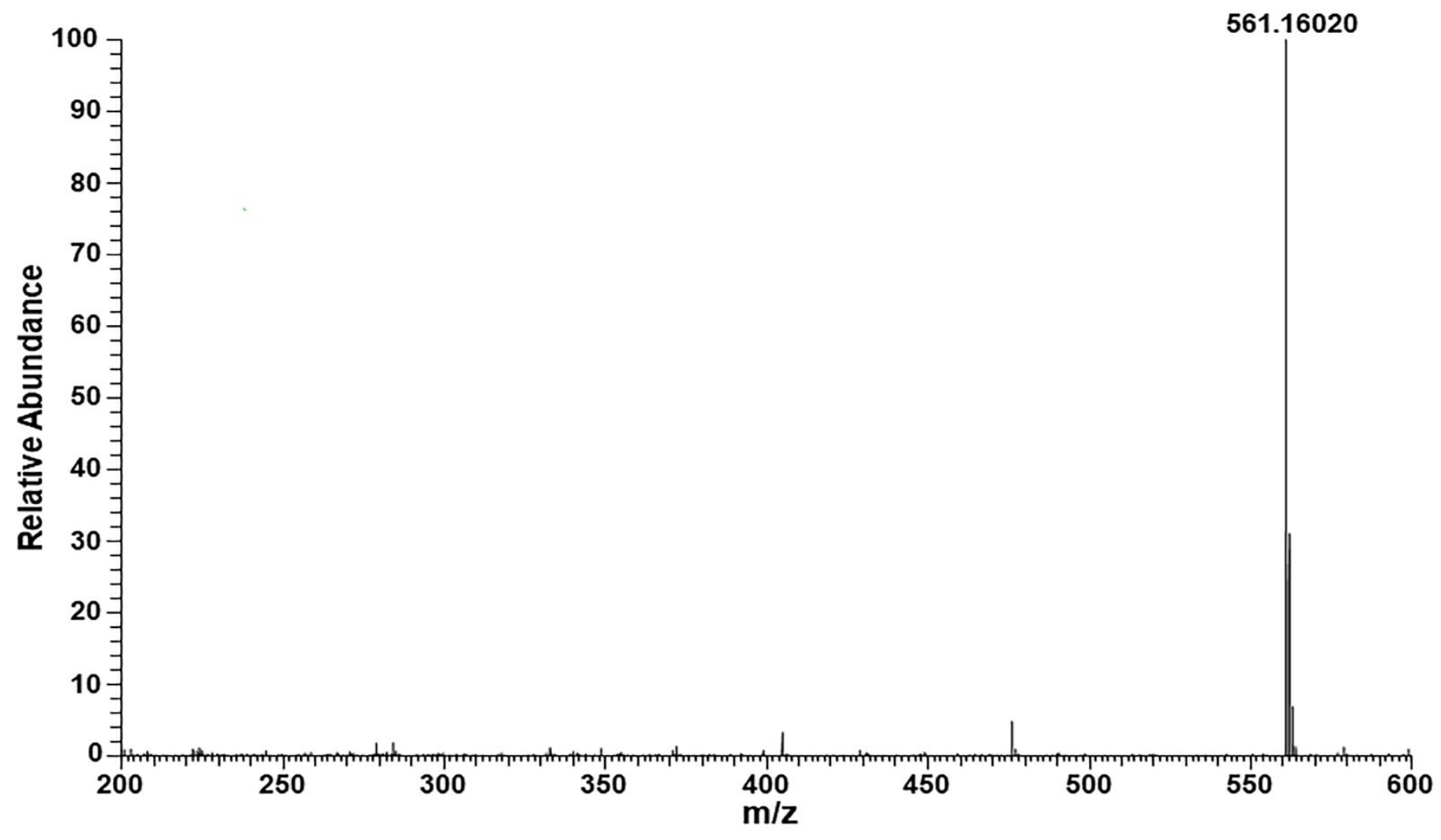


Figure S8. High-resolution mass spectrum $\left(\mathrm{MS}^{2}\right)$ of C3G-2ACR

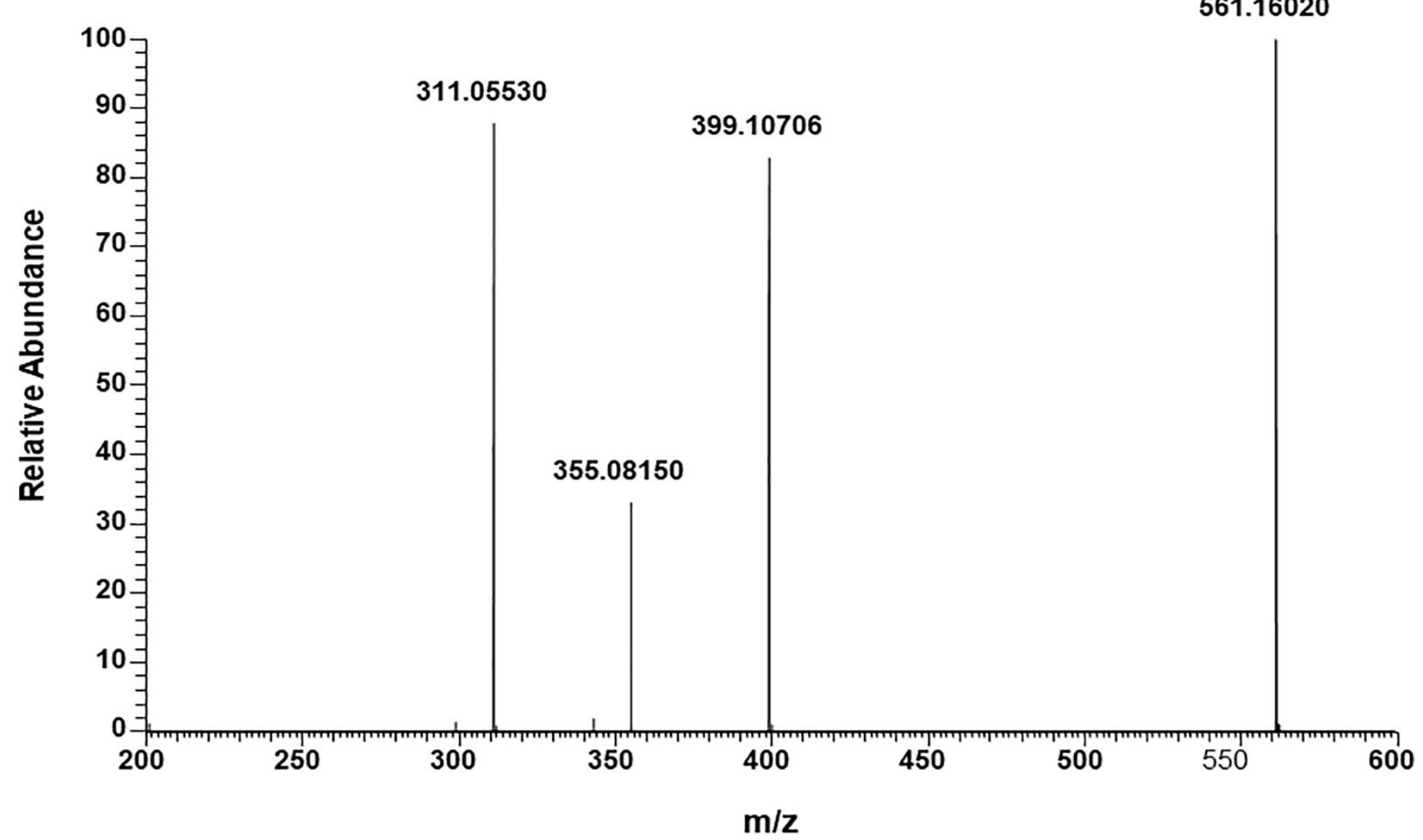


Figure S9. ${ }^{1} \mathrm{H}-\mathrm{NMR}$ spectrum of $\mathrm{C} 3 \mathrm{G}-2 \mathrm{ACR}$

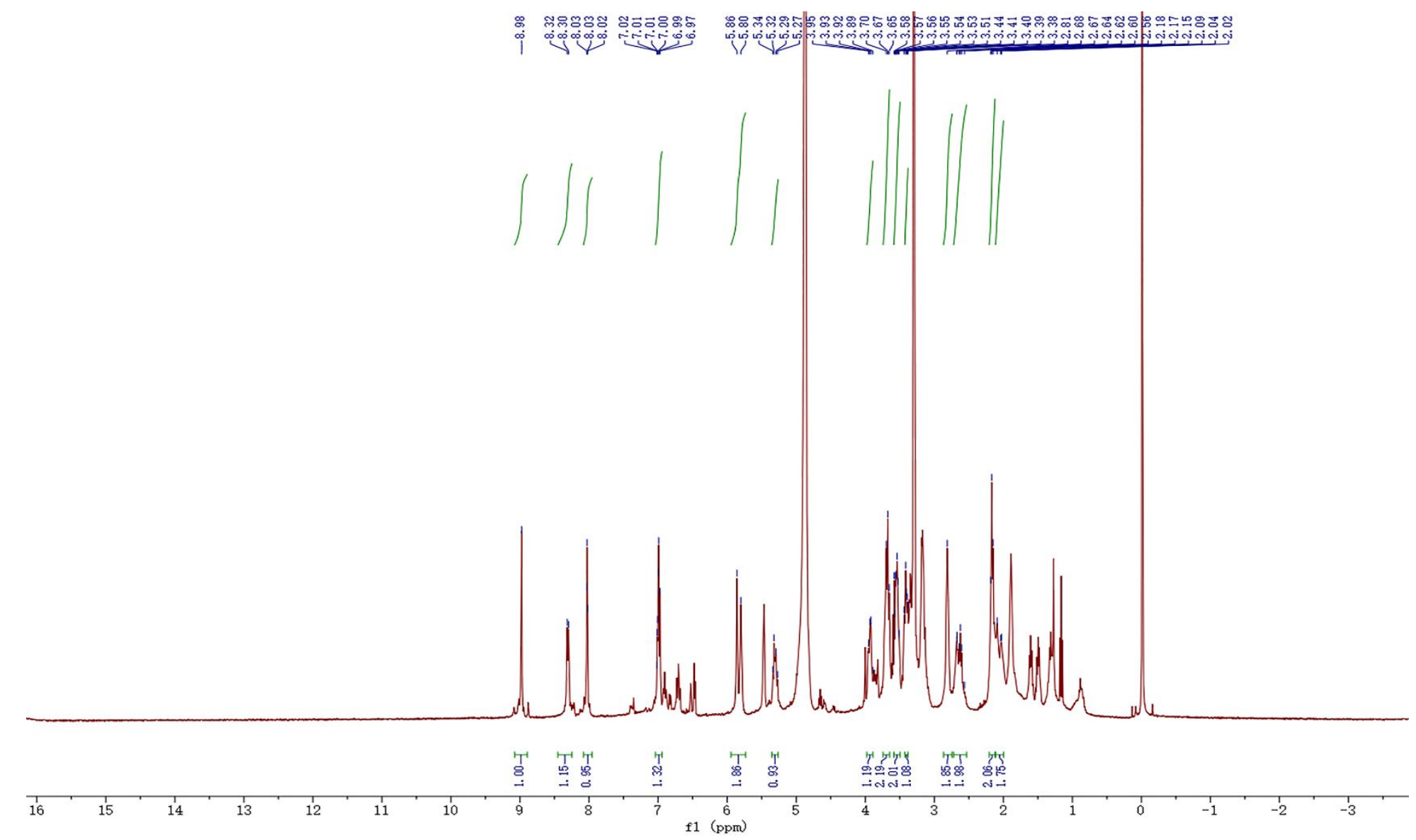


Figure $\mathrm{S} 10 .{ }^{13} \mathrm{C}-\mathrm{NMR}$ spectrum of $\mathrm{C} 3 \mathrm{G}-2 \mathrm{ACR}$

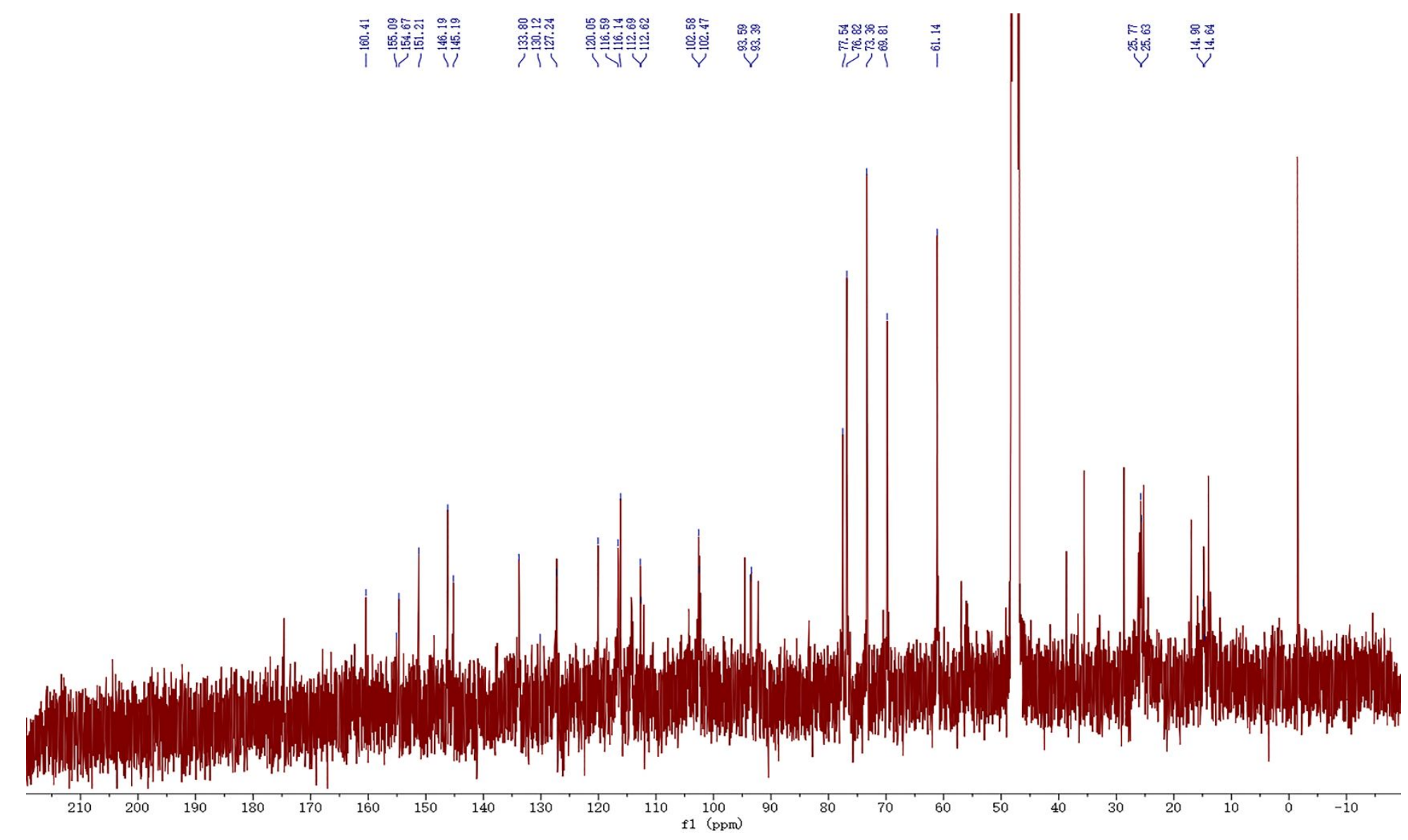


Figure S11. HSQC-NMR spectrum of C3G-2ACR

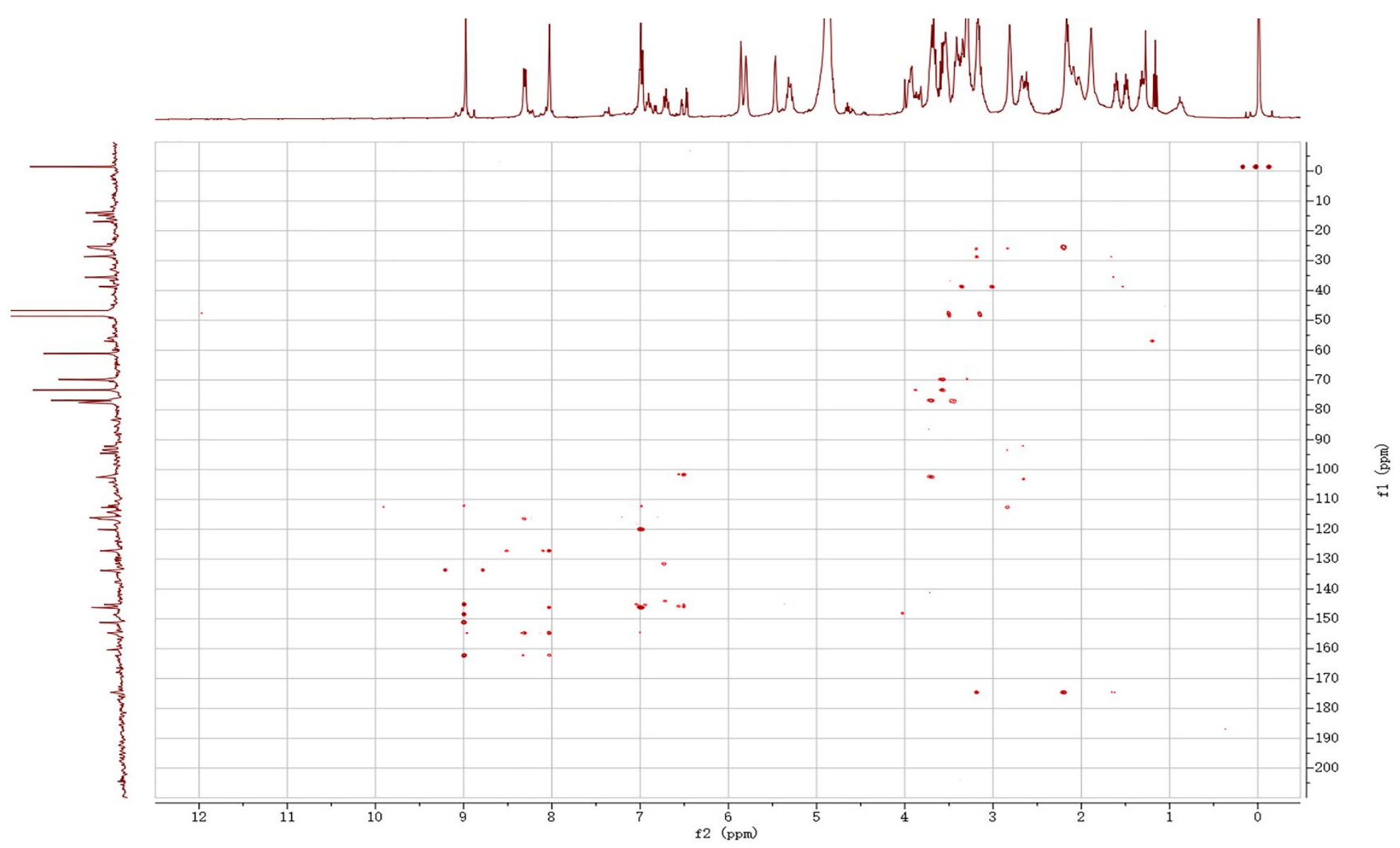


Figure S12. HMBC-NMR spectrum of C3G-2ACR

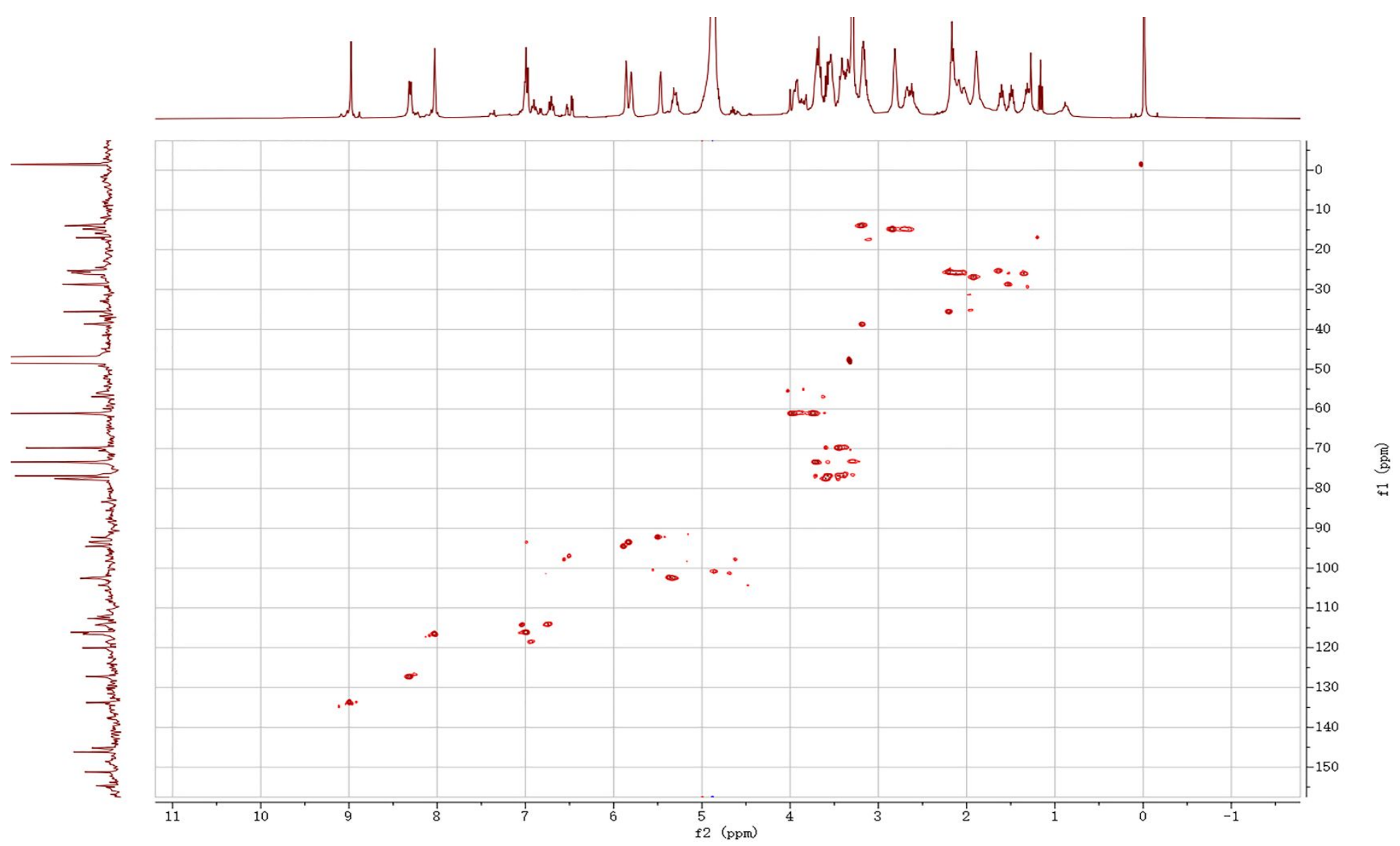


Figure S13. HPLC-DAD chromatogram of the main flavonoids in myrica red

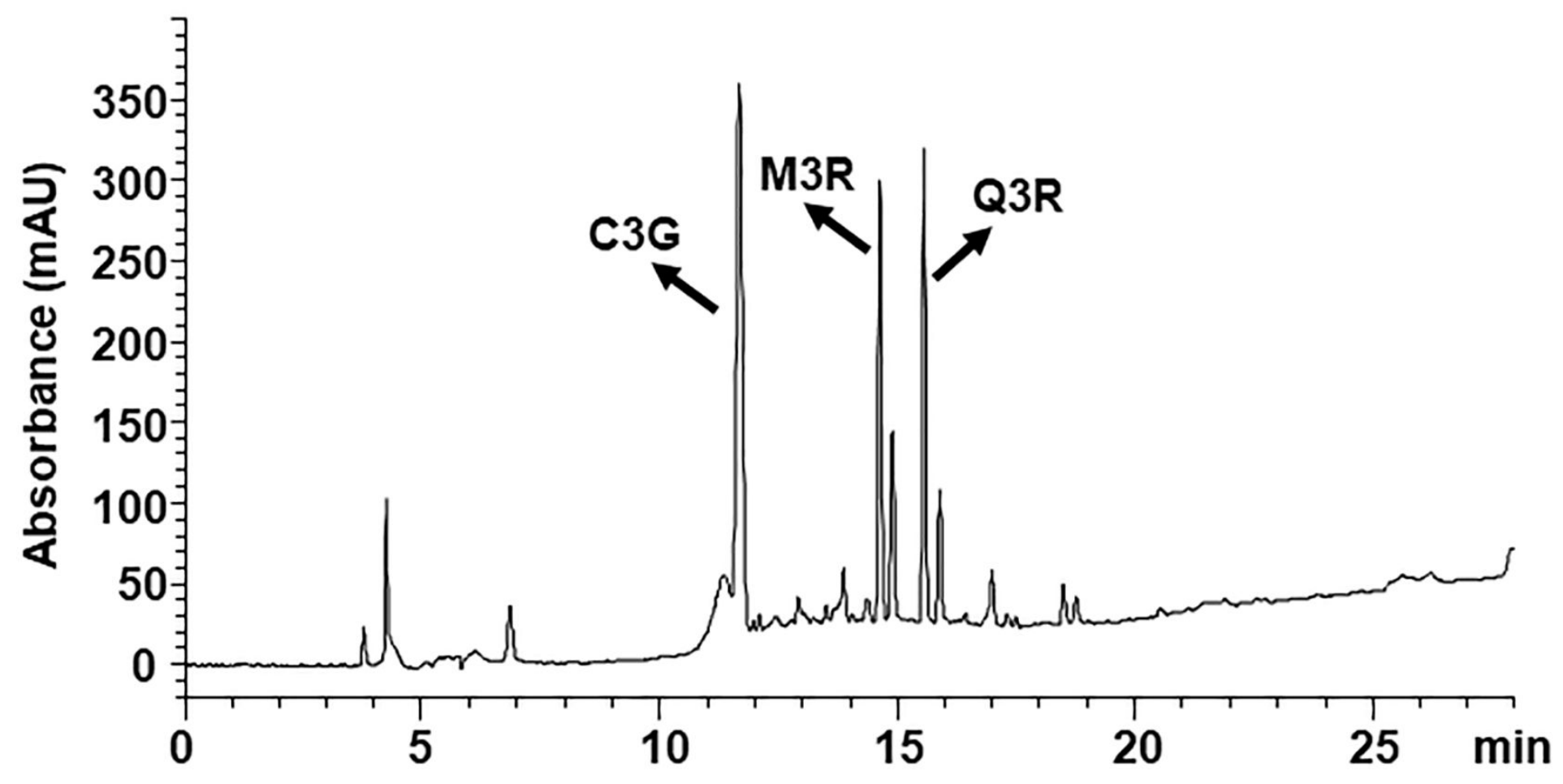


Figure S14 LC-MS/MS data of C3G, Q3R and M3R in mynica red.

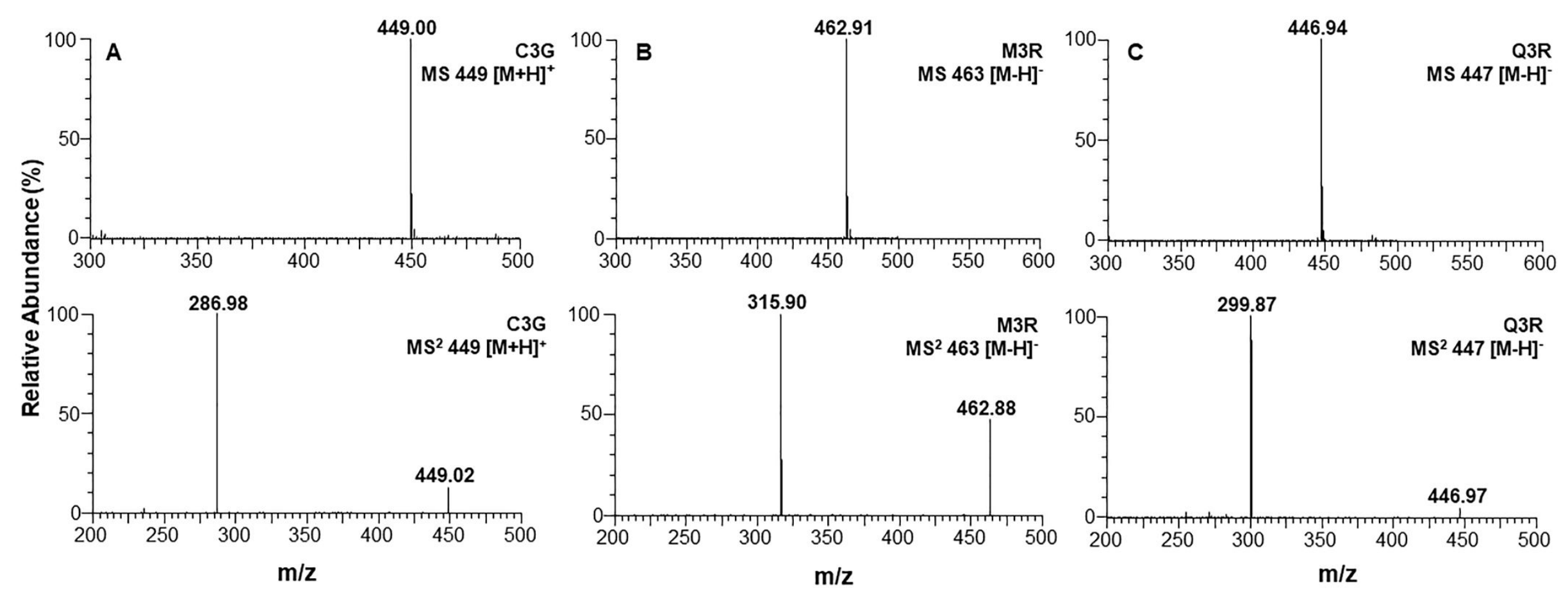

